Harvesting traffic-induced vibrations for structural health monitoring of bridges

This article has been downloaded from IOPscience. Please scroll down to see the full text article.

2011 J. Micromech. Microeng. 21104005

(http://iopscience.iop.org/0960-1317/21/10/104005)

View the table of contents for this issue, or go to the journal homepage for more

Download details:

IP Address: 141.211.173.82

The article was downloaded on 06/04/2012 at 16:04

Please note that terms and conditions apply. 


\title{
Harvesting traffic-induced vibrations for structural health monitoring of bridges
}

\author{
T V Galchev, J McCullagh, R L Peterson and K Najafi \\ Center for Wireless Integrated Microsystems (WIMS), University of Michigan, 1301 Beal Ave., \\ Ann Arbor, MI 48109-2122, USA \\ E-mail: tgalchev@umich.edu
}

Received 4 April 2011, in final form 16 June 2011

Published 29 September 2011

Online at stacks.iop.org/JMM/21/104005

\begin{abstract}
This paper discusses the development and testing of a renewable energy source for powering wireless sensors used to monitor the structural health of bridges. Traditional power cables or battery replacement are excessively expensive or infeasible in this type of application. An inertial power generator has been developed that can harvest traffic-induced bridge vibrations. Vibrations on bridges have very low acceleration $\left(0.1-0.5 \mathrm{~m} \mathrm{~s}^{-2}\right)$, low frequency $(2-30 \mathrm{~Hz})$, and they are non-periodic. A novel parametric frequency-increased generator (PFIG) is developed to address these challenges. The fabricated device can generate a peak power of $57 \mu \mathrm{W}$ and an average power of $2.3 \mu \mathrm{W}$ from an input acceleration of $0.54 \mathrm{~m} \mathrm{~s}^{-2}$ at only $2 \mathrm{~Hz}$. The generator is capable of operating over an unprecedentedly large acceleration $\left(0.54-9.8 \mathrm{~m} \mathrm{~s}^{-2}\right.$ ) and frequency range (up to $30 \mathrm{~Hz}$ ) without any modifications or tuning. Its performance was tested along the length of a suspension bridge and it generated $0.5-0.75 \mu \mathrm{W}$ of average power without manipulation during installation or tuning at each bridge location. A preliminary power conversion system has also been developed.
\end{abstract}

(Some figures in this article are in colour only in the electronic version)

\section{Introduction}

There is a recognized need to monitor the health of civil, mechanical and aerospace structures [1]. Recently, there has been strong interest in leveraging wireless technology in structural health monitoring (SHM) applications [2]. Wireless sensor technology has the potential to have a great impact on this field including reducing the cost, increasing the adoptability of SHM systems, and increasing the density of data that can be collected from a given structure. However, the availability of renewable energy is a key challenge in the realization of wireless SHM and other remote sensing systems. Wired energy is not a good option because wires are physically vulnerable and expensive to install and to maintain [3]. In fact, this is one of the reasons why wireless technology is so attractive in SHM applications. Batteries and other stored energy means can be used; however, multiple replacements will be needed through the lifetime of the system. Each replacement will carry with it a significant cost. Since typical applications require a dense network of sensors, the cost of non-renewable energy is a formidable barrier to the adoption of wireless monitoring systems.
Bridges are prime candidates for wireless SHM systems. In the United States highway bridges undergo a visual inspection every 2 years [2]. This is not sufficient to ensure the safety and reliability of this aging and deteriorating transportation infrastructure. As of December 2009, the US Department of Transportation rates 71179 bridges as structurally deficient and 78468 as functionally obsolete [4], which constitutes $25 \%$ of the 603254 bridges in total. Between 1989 and 2000 there have been 503 bridge collapses in the United States [5]; however, only the most severe, such as the 2007 I-35W bridge collapse in Minnesota, garner media attention.

Bridges pose a wealth of available ambient energy that can be exploited for powering SHM systems including, solar [6], wind [7], thermal [8], RF [9, 10] and vibrations [8, 11-13]. Each energy source poses specific challenges that must be overcome. Solar energy promises the largest energy density; however, challenges associated with the availability of sunlight and the accumulation of debris on the solar cell over long periods of time have to be resolved. The availability of wind can vary greatly from location to location and wind harvesters tend to be bulky. Thermal harvesters 
present challenges with installation and making a good thermal connection to the bridge, as well as maintaining a large gradient across the harvester. Ambient RF energy comes in many varieties, medium and shortwave frequencies, UHF and SHF bands, or alternatively energy can be broadcast by a local host. These sources all have tradeoffs such as practicality, antenna design and available RF power. Finally, there is plenty of kinetic energy generated as the bridge vibrates in response to the vehicular traffic passing on top of it. While there are plenty of vibrations, this energy comes in a form that is difficult to harvest, because the bridge vibrations are low frequency, non-periodic and they have small amplitudes. Before this study there is only a single example of a vibration harvester installation on a bridge [11]; however, that device was installed at only one location and had to be tuned to the ambient vibration characteristics.

This paper presents the design, fabrication and testing of an inertial micro power generation system for scavenging traffic-induced bridge vibrations. It is based on the parametric frequency increased generator (PFIG) architecture [14, 15], which is ideally suited toward scavenging low-frequency nonperiodic vibrations without the need for any modifications or tuning during installation. Preliminary bench top test results from this system were presented in [16]. This paper will discuss the detailed design and development of the entire vibration harvesting system. The mechanical harvester performance has been evaluated on the New Carquinez (NC) bridge in Valejo, California. Section 2 will outline the feasibility of harvesting vibration energy on bridges. Section 3 discusses the design and development of a PFIG for harvesting bridge vibrations. Test results from laboratory characterization as well as field installation on the NC bridge are presented in section 4. Section 5 will discuss initial attempts to form a complete harvester system by designing and implementing a power conversion block to rectify and boost the ac voltage from the PFIG. Section 6 discusses the performance of the harvester compared with the state of the art and presents ideas about future work. Conclusions about the study are drawn in section 7 .

\section{Availability and characteristics of bridge vibrations}

The goal of this effort was to design a vibration harvester that is capable of operating on a variety of different bridge structures, and in multiple locations on a given bridge, without the need to modify or tune it during operation and installation. For this purpose, the vibrations on two very different types of bridges were studied. One was the Grove Street (GS) highway flyover steel girder-concrete deck composite structure located in Ypsilanti, Michigan, and the other was the NC suspension bridge in Valejo, California. Twenty sensor placements were used to measure the vibrations on the deck of the GS bridge and 11 on the NC structure. A tri-axial accelerometer (Crossbow CXL02TG3) was used, sampled at $100 \mathrm{~Hz}$. Acceleration recordings were made for several minutes by each sensor under routine traffic loads. A typical acceleration waveform from the NC bridge is shown in figure 1. Peak accelerations

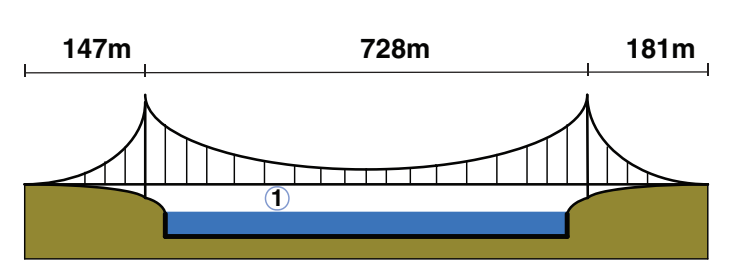

(1)
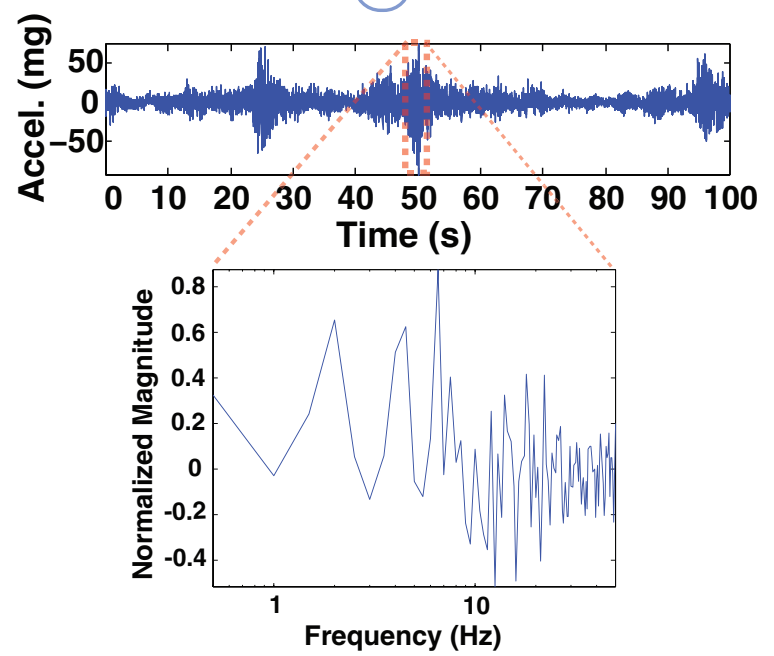

Figure 1. Acceleration measurement on the deck of the NC Bridge in Valejo, California. The circled number represents the sensor location. Acceleration peaks in the $30-50 \mathrm{mg}(1 \mathrm{mg}=9.8 \times$ $10^{-3} \mathrm{~m} \mathrm{~s}^{-2}$ ) range can be seen. The bottom picture shows the frequency response of a sample of the data. In addition to the small amplitude, traffic-induced vibrations are low in frequency and have a broad spectrum with no clearly identifiable peak.

on the NC bridge are in the $10-130 \mathrm{mg}$ range $(1 \mathrm{mg}=$ $9.8 \times 10^{-3} \mathrm{~m} \mathrm{~s}^{-2}$ ), and $10-35 \mathrm{mg}$ range for the GS structure [17]. Lower accelerations can be found around the anchor points and in the middle of the suspension bridge. These data are in close agreement with measurements performed on other bridges worldwide $[12,13]$. The arbitrary nature of the vibration is confirmed by taking the discrete Fourier transform of the data. The frequency domain plot of the sensor data presented in figure 1 is also included in the graphic. The spectral content is mostly contained within the very low end of the frequency spectrum $(2-30 \mathrm{~Hz})$ with no identifiable peak. In fact, the frequency domain characteristics change from location to location, from the NC to the GS bridges, and they vary in time at a single location [17].

The analysis of the bridge vibrations indicates that a vibration harvester would have to be able to generate energy from acceleration in the range of 15-30 mg. Additionally, such a device would have to have a wide bandwidth $(\leqslant 30 \mathrm{~Hz})$ in order to operate on a variety of bridges and locations. A simple analysis can help confirm that in fact practical amounts of energy can be extracted from bridge vibrations. The ideal maximum power that can be converted by an inertial power generator is given by [18]

$$
\text { Power }_{\max }=\frac{2}{\pi} Y_{o} Z_{\max } \omega^{3} m
$$

where the input vibration has amplitude $Y_{o}$ and frequency $\omega$, $Z_{\max }$ is the maximum displacement of the inertial mass in one 


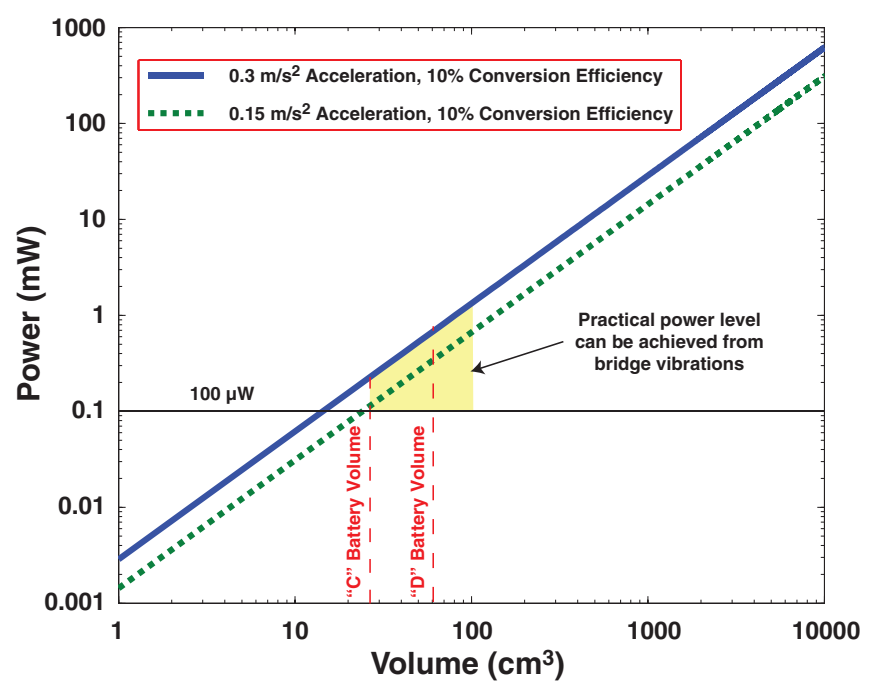

Figure 2. Plot showing the maximum power that can be converted by an inertial power generator with an efficiency of $10 \%$, as a function of volume, from a vibration of 15 and $30 \mathrm{mg}$ both occurring once per second.

direction and $m$ is the mass. In this analysis the generator is assumed to have a cubic geometry, where half of the volume is occupied by the mass (density of $20 \mathrm{~g} \mathrm{~cm}^{-3}$ ), and the other half is available for motion. Therefore, $Z_{\max }$ is $\frac{1}{4}$ of the linear dimension of the generator. Figure 2 shows the results of this analysis for accelerations of 15 and $30 \mathrm{mg}$. Here the vibrations are harmonic with a frequency of $1 \mathrm{~Hz}$. Additionally, the generator's efficiency is assumed to be $10 \%$. From this simple calculation it is clear that a window of opportunity exists to generate a substantial amount of power within a reasonable volume for powering wireless SHM sensors. In fact, more than $100 \mu \mathrm{W}$ can be generated within the volume of a ' $C$ ' size battery $\left(\sim 27 \mathrm{~cm}^{3}\right)$.

\section{Bridge harvester design and implementation}

Due to the low frequency and non-periodic nature of the bridge vibrations, it is clear that a typical resonant harvester will not be effective. The mechanical harvester is designed as a non-resonant PFIG [14]. A conceptual illustration of the cross-section of a typical PFIG is shown in figure 3(a). The PFIG has a large centrally located mass that moves in response to the external displacement of the generator frame. The motion of this compliant mechanism is used to induce highfrequency mechanical oscillations in an electromechanical transducer. This mechanical transformation decouples the internal operation of the harvester from the ambient vibration frequency providing two important benefits: (1) by upconverting $[19,20]$ the ambient vibration frequency, the PFIG achieves better electromechanical coupling and efficiency in converting the low-frequency bridge vibrations, and (2) the decoupled non-resonant operation of the device allows it to function in the unpredictable bridge environment. The electromechanical transducers are located above and below the inertial mass and they are referred to as frequency increased generators (FIGs). In the present implementation,

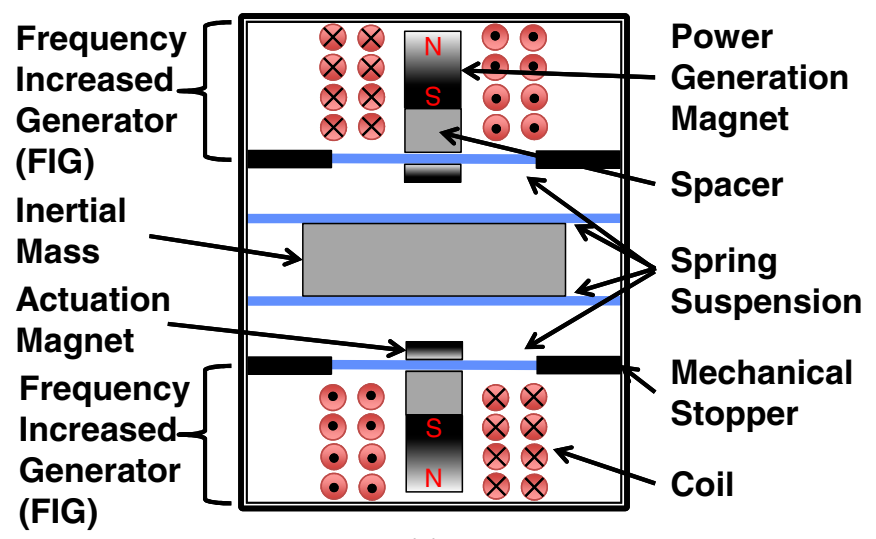

(a)

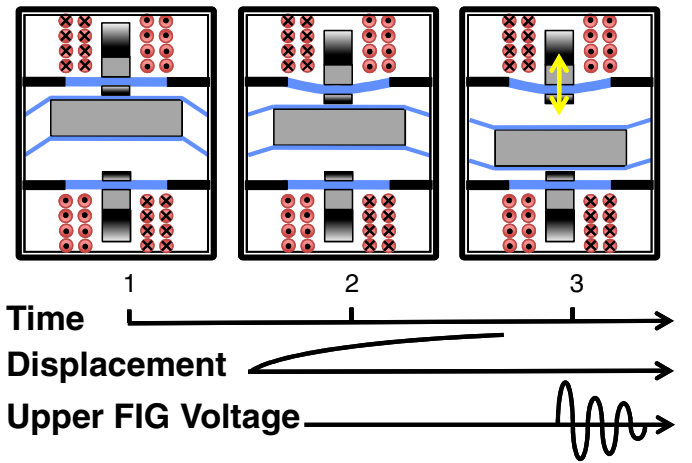

(b)

Figure 3. (a) Conceptual illustration of the PFIG architecture. (b) Depiction of the PFIG method of operation.

electromagnetic transduction is used. The large inertial mass couples kinetic energy from the ambient inside the generator structure, and through a magnetic latching mechanism passes a portion of this energy to either one of the FIGs. The operation of the PFIG is outlined in figure $3(b)$. The inertial mass moves back and forth between the two FIG generators, attaching magnetically. As the inertial mass moves, it pulls the FIG spring along until a force imbalance on the FIG/inertial mass system causes the two to separate. The inertial mass detaches and is pulled to the opposing FIG. The freed FIG resonates at its high natural frequency converting the stored mechanical energy in its spring, into electrical energy. This process is subsequently repeated in the opposite direction.

\subsection{Harvester structure}

The physical implementation of the generator can be seen in figure 4. It is housed within an aluminum case. The inertial mass is made out of tungsten carbide (WC) and can be seen in the middle, with the two electromagnetic FIGs positioned above and below it. It is suspended from both sides using copper springs. This suspension scheme is used in order to reduce unwanted out-of-axis motion.

Each FIG consists of an outer case with a hole bored though the middle, where a secondary enclosure containing the transduction components is able to move in the vertical direction. This enclosure is held in place using setscrews from the sides and from the bottom. The built in motion range is used 


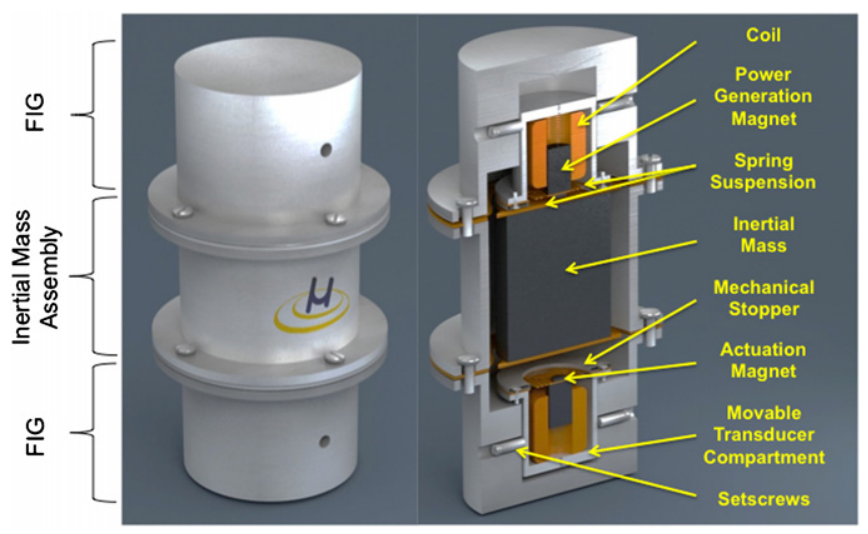

Figure 4. Illustration of the bridge PFIG harvester implementation. A large inertial mass can be seen suspended in the middle and held between the two FIGs positioned on top and on the bottom. The FIG transduction components are inside a movable internal compartment that can be repositioned to remove unwanted biasing due to gravity.

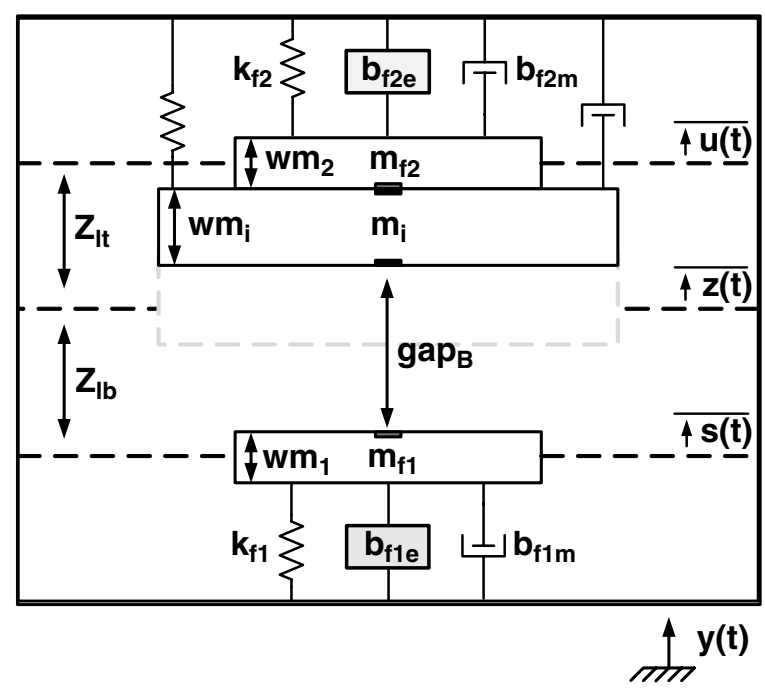

Figure 5. Mechanical model of the bridge PFIG harvester.

to remove the bias of gravity from the mechanical system by adjusting the equilibrium position of the PFIG system. While it is possible to calculate the gravity bias and build in the needed adjustment, because of the large weight of the inertial mass, small manufacturing errors in the springs can lead to large changes in position. Also, the ambient acceleration is very small and the inertial mass deflections will be quite limited, thus mis-positioning caused by gravity can have significant negative consequences for harvester operation.

\subsection{Modeling the PFIG harvester}

The PFIG can be mechanically modeled as three massspring-damper systems that influence each other through two magnetic latching mechanisms. The mechanical model of the PFIG is shown in figure 5 . The inertial mass $m_{i}$ is suspended by a low-stiffness spring $k_{i}$. The viscous damper with constant $b_{i}$ accounts for parasitic damping of the inertial mass. The two FIG devices are represented by mass $m_{f x}$, spring $k_{f x}$, parasitic damper $b_{f x m}$ and electrical damper $b_{f x e}$. The ' $x$ ' in each of these variables refers to FIG1 (bottom) or FIG2 (top). The electromechanical transduction is modeled as a viscous damping force with damping constant $b_{f x e}$. The inertial mass, FIG1 and FIG2 motion relative to the generator frame are denoted by $z(t), s(t)$ and $u(t)$, respectively. A distance of $Z_{l b}$ and $Z_{l t}$ separates the rest positions of FIG1 and FIG2 relative to the equilibrium position of the inertial mass. Lastly, $\operatorname{gap}_{T}$ and $\operatorname{gap}_{B}$ denote the physical distance between the inertial mass and the top of each FIG when the inertial mass is latched on to the bottom and top FIGs respectively, as is the situation depicted in figure 5. For visualization purposes, each mechanical element is given a width $w m_{x}$.

The PFIG mechanical system has two sources of nonlinearity: (1) the magnetic force in the latching mechanism, and (2) the discontinuity generated as the system transitions from having two degrees of freedom when the inertial mass is attached to a FIG, to three degrees of freedom when all three mechanical elements are moving relative to each other. Due to the nonlinearity of the system, dynamic analysis is the only way to evaluate the behavior of the PFIG. For the purposes of modeling the PFIG, its operation is broken into three distinct continuous cases:

(1) Case 1: inertial mass is latched on to the top FIG, and the PFIG has two degrees of freedom. Case 1 is depicted in figure 5 .

(2) Case 2: opposite of case 1, the inertial mass is latched on to the bottom FIG.

(3) Case 3: inertial mass is not latched to either FIG, and all three mechanisms can move (three degrees of freedom).

Considering first the dynamics of case 1, the system consists of two coupled second-order differential equations. The motion of the combined inertial mass/FIG mechanism is given by

$$
\begin{aligned}
& \left(m_{i}+m_{f 2}\right) \ddot{u}+b_{f 2 e} \dot{u}+b_{f 2 m} \dot{u}+b_{i} \dot{u}+k_{f 2} u+k_{i}\left(u+\operatorname{gap}_{T}\right) \\
& \quad=-\left(m_{i}+m_{f 2}\right) \ddot{y}-F_{\mathrm{mag}, 1 i} .
\end{aligned}
$$

Similarly, the motion of FIG2 follows as

$$
m_{f 1} \ddot{s}+b_{f 1 e} \dot{s}+b_{f 1 m} \dot{s}+k_{f 1} s=-m_{f 1} \ddot{y}+F_{\text {mag }, i 1} .
$$

The two magnetic forces $F_{\mathrm{mag}, 1 i}$ and $F_{\mathrm{mag}, i 1}$ in (2) and (3) are equal in magnitude and opposite in direction. They represent the force that FIG1 exerts on the bottom of the inertial mass due to the magnetic latching mechanism and vice versa. An approximation to the force between two nearby magnetized surfaces is given by

$$
F_{\text {mag }}=\frac{B^{2} A}{2 \mu_{o}},
$$

where $B$ is the magnetic flux density, $A$ is the area of each surface, and $\mu_{o}$ is the permeability of free space $\left(\mu_{o}=4 \pi \times\right.$ $10^{-7} \mathrm{~T} \mathrm{~m} \mathrm{~A}^{-1}$ ). An estimate of the magnetic flux at a point along the central axis of a rectangular magnet is given by [20]

$$
\begin{aligned}
B= & \frac{B_{r}}{\pi}\left(\tan ^{-1}\left(\frac{W L}{2 d \sqrt{4 d^{2}+W^{2}+L^{2}}}\right)\right. \\
& \left.-\tan ^{-1}\left(\frac{W L}{2(d+T) \sqrt{4(d+T)^{2}+W^{2}+L^{2}}}\right)\right) .
\end{aligned}
$$


The flux density is computed a distance $d$ from a magnet with length $L$, width $W$, thickness $T$ and residual flux density $B_{r}$. The distance, $d$, is a function of the positions of the combined system, $u(t)$, the position of FIG1, $s(t)$, as well as the physical properties of the system, $Z_{l b}, Z_{l t}, w m_{1}, w m_{2}$ and $w m_{i}$.

$$
d=u-s+\left[Z_{l t}+Z_{l b}-0.5 w m_{1}-0.5 w m_{2}-w m_{i}\right] .
$$

The distance simplifies to $\operatorname{gap}_{B}$ when $u$ and $s$ are both zero and the devices are at rest. When the system is in case 1 or case 2 , the position of the inertial mass is reflected by the coordinate $u(t)$, and it can be transformed back to its own axis by the expression

$$
z(t)=u(t)+Z_{l t}-0.5 w m_{2}-0.5 w m_{i} .
$$

This representation of the dynamics of case 1 remains true as long as a normal force, $T$, exerted by the inertial mass on FIG2 remains opposite in direction to the relative position of the inertial mass with respect to FIG2 and greater than zero. The normal force applied to FIG2 by the inertial mass is given by

$$
T=m_{f 2} \ddot{u}+b_{f 2 e} \dot{u}+b_{f 2 m} \dot{u}+k_{f 2} u+F_{\mathrm{mag}, 2 i} .
$$

Once $T \leqslant 0$, case 1 is no longer valid and the PFIG enters case 3, where the two FIGs and the inertial mass are moving independently.

Case 2 is nearly identical to case 1 except for a number of sign changes that occur because the relative position of the FIG to the inertial mass is inverted.

When the inertial mass detaches from either of the two FIGs, the system enters case 3 . In this case, the equations of motion of the three separate mechanical systems are given by

$$
\begin{gathered}
m_{f 2} \ddot{u}+b_{f 2 e} \dot{u}+b_{f 2 m} \dot{u}+k_{f 2} u=-m_{f 2} \ddot{y}-F_{\mathrm{mag}, i 2} \\
m_{f 1} \ddot{s}+b_{f 1 e} \dot{s}+b_{f 1 m} \dot{s}+k_{f 1} s=-m_{f 1} \ddot{y}+F_{\mathrm{mag}, i 1} \\
m_{i} \ddot{z}+b_{i} \dot{z}+k_{i} z=-m_{i} \ddot{y}+F_{\mathrm{mag}, 2 i}-F_{\mathrm{mag}, 1 i} .
\end{gathered}
$$

The motion of the three systems remains coupled by the magnetic latching forces. These magnetic forces can again be calculated using (5) and taking into account the appropriate distance as

$$
\begin{aligned}
d_{2-i} & =u-z+\left[Z_{l t}-0.5 w m_{2}-0.5 w m_{i}\right], \\
d_{1-i} & =z-s+\left[Z_{l b}-0.5 w m_{1}-0.5 w m_{i}\right] .
\end{aligned}
$$

The position of the inertial mass is used to determine the validity of case 3 . If either of the following statements is true

$$
\begin{gathered}
z(t) \geqslant u(t)+\left(Z_{l t}-0.5 w m_{2}-0.5 w m_{i}\right) \\
z(t) \leqslant s(t)-\left(Z_{l t}-0.5 w m_{1}-0.5 w m_{i}\right),
\end{gathered}
$$

then the inertial mass has made contact with one of the FIGs and case 3 is no longer valid. When the inertial mass makes contact with each of the FIG devices, some energy is lost from the ensuing collision. The impact between the inertial mass and the FIG is modeled as an elastic collision and the initial and final velocities of the colliding masses are given by

$$
V_{i, \text { final }}=\frac{\left(C_{R}+1\right) m_{f x} V_{f x}+V_{i}\left(m_{i}-C_{R} m_{f x}\right)}{m_{i}+m_{f x}}
$$

Table 1. Summary of the PFIG mechanical parameters.

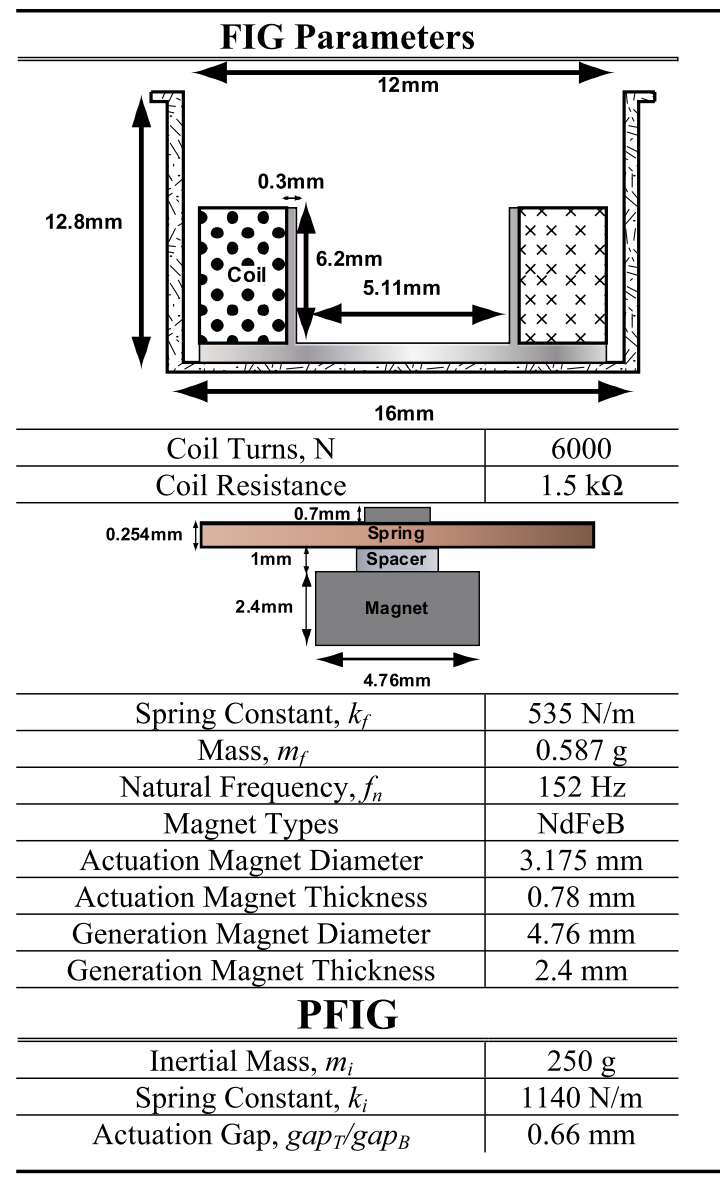

$$
V_{f x, \text { final }}=\frac{\left(C_{R}+1\right) m_{i} V_{i}+V_{i}\left(m_{f x}-C_{R} m_{i}\right)}{m_{i}+m_{f x}},
$$

where $C_{R}$ is the coefficient of restitution of the materials coming into contact, $V_{i}$ and $V_{f x}$ are the initial velocities of the inertial mass and the appropriate FIG device, respectively, and $m_{i}$ and $m_{f x}$ are the inertial mass and the FIG mass respectively. The ensuing velocities can be used to prime either the case 1 or case 2 system, ensuring that linear momentum is conserved. While this modeling of the collision is simplistic and some detail is lost in the abstraction, the overall model of the PFIG has been found to be of sufficient accuracy.

By utilizing this piecewise continuous model of the PFIG, its dynamic behavior can be analyzed numerically using an appropriate software tool such as MATLAB. In this manner, stable configurations for the generator can be determined, and one can even optimize the system using sophisticated numerical algorithms.

\subsection{PFIG fabrication}

A summary of the PFIG design is given in table 1 . It is fabricated using a combination of lithographic and conventional means. The external PFIG components are milled out of aluminum. The inertial mass was machined out of a $2.54 \mathrm{~cm}$ diameter tungsten carbide rod using electro 

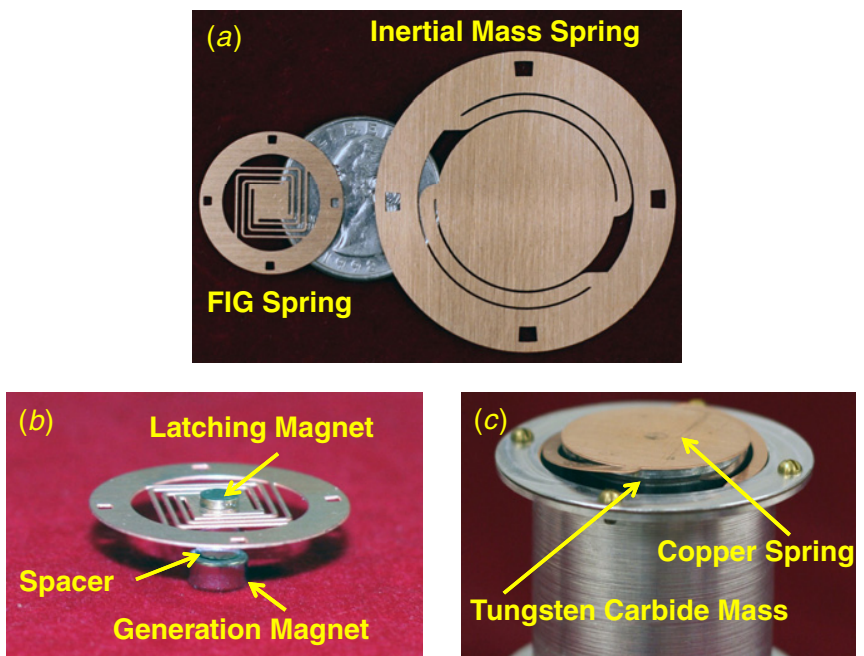

Figure 6. Photographs showing (a) the fabricated springs for the FIG and inertial mass, $(b)$ the FIG assembly including the spring and magnets for latching and power generation and $(c)$ the assembled inertial mass and spring component.

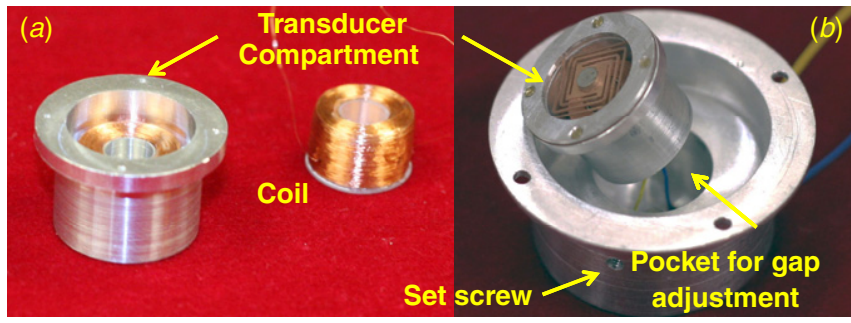

Figure 7. Photographs of $(a)$ the assembled transducer compartment and a wound coil, and $(b)$ a close-up of the fabricated FIG and movable transducer.

discharge machining (EDM). The springs for both the FIG and the inertial mass are fabricated out of $250 \mu \mathrm{m}$ thick copper alloy. The copper is patterned using a double-sided spray etching process. Fabricated springs for both the inertial mass and the PFIG are shown in figure $6(a)$. The spring assemblies for both the inertial mass and the FIG are put together using epoxy. An alignment jig is used to center the components. An NdFeB N42 grade $(4.76 \mathrm{~mm}$ diameter and $2.4 \mathrm{~mm}$ thickness) magnet is used for power generation. A smaller $3 \mathrm{~mm}$ diameter magnet comprises the latching mechanism. The finished spring assemblies for both the inertial mass and the FIGs are shown in figures $6(b)$ and (c). Coils are made from $50 \mu \mathrm{m}$ diameter enameled copper wire wound around specially machined aluminum bobbins and screwed in place within the transducer compartment. A photograph of one of the coils is shown in figure $7(a)$ and the fully assembled FIG in figure $7(b)$. The finished PFIG measures $3.3 \mathrm{~cm}$ in diameter and is $7.3 \mathrm{~cm}$ tall. The internal volume of the device, including all of the transduction mechanisms, the inertial mass and all of the space needed for the components to move is $43 \mathrm{~cm}^{3}\left(68 \mathrm{~cm}^{3}\right.$ including the casing). The finished device is shown in figure 8 .

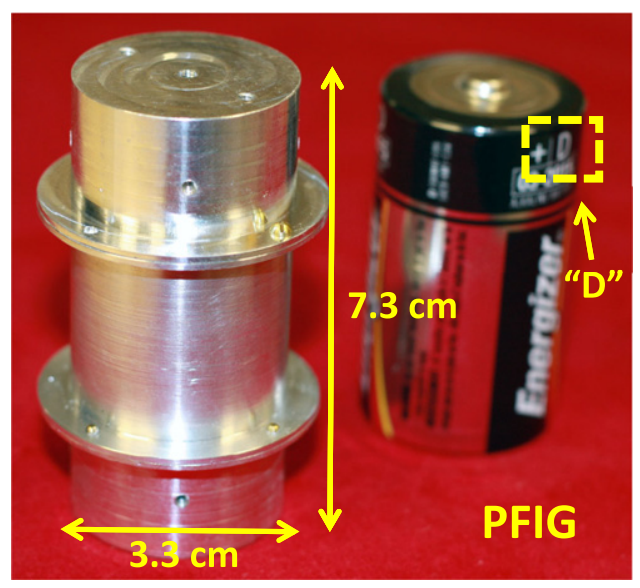

Figure 8. Photograph showing the completed PFIG alongside a standard ' $D$ ' size battery.

\section{Harvester results and testing}

The PFIG harvester was first characterized under sinusoidal excitation. It was mounted on an APS Dynamics APS113 long stroke linear shaker. A driving waveform was generated by an Agilent 33250A signal generator and amplified using an APS Model 124 amplifier. The resultant shaker acceleration was monitored using an ADXL203 accelerometer. Each FIG was loaded with a $1.5 \mathrm{k} \Omega$ resistor, in order to match its output impedance, and the voltage across the load was recorded. The harvester was found to be capable of operating from accelerations as low as $55 \mathrm{mg}$. This is within the range of acceleration found on typical bridges.

\subsection{Harvester characterization}

The frequency response to an acceleration range of $0.055-1 \mathrm{~g}$ was measured and the results are presented in figure 9. This is a span of almost two full orders of magnitude, which constitutes an unprecedented operation range. These measurements were performed without any modifications or tuning to the PFIG. At $55 \mathrm{mg}$ the shaker table can be accurately controlled down to $2 \mathrm{~Hz}$. At this frequency the PFIG generates and average power of $2.3 \mu \mathrm{W}(57 \mu \mathrm{W}$ peak power).

The voltages waveforms generated by the two FIGs when actuated using a periodic acceleration of $55 \mathrm{mg}$ at 2 and $10 \mathrm{~Hz}$ are shown in figure 10 . The sequential excitation of the FIGs due to the inertial mass attachment and subsequent detachment from each FIG are evident from the measured signals. When operating at $2 \mathrm{~Hz}$, the velocity of the combined system, inertial mass and FIG is low. Therefore all dynamic forces (mechanical damping, FIG and mass inertial forces) are negligible. This velocity-limited regime is analyzed in depth in [17]. The release distance is mainly governed by the magnitude of the magnetic force of attraction in relation to the opposite force provided by the deflecting FIG spring. It results in the smallest possible FIG actuation distance while still maintaining operation of the PFIG and unlatching of the inertial mass. Consequently, the peak voltage of the $2 \mathrm{~Hz}$ waveform is smaller, as compared with the waveform at 


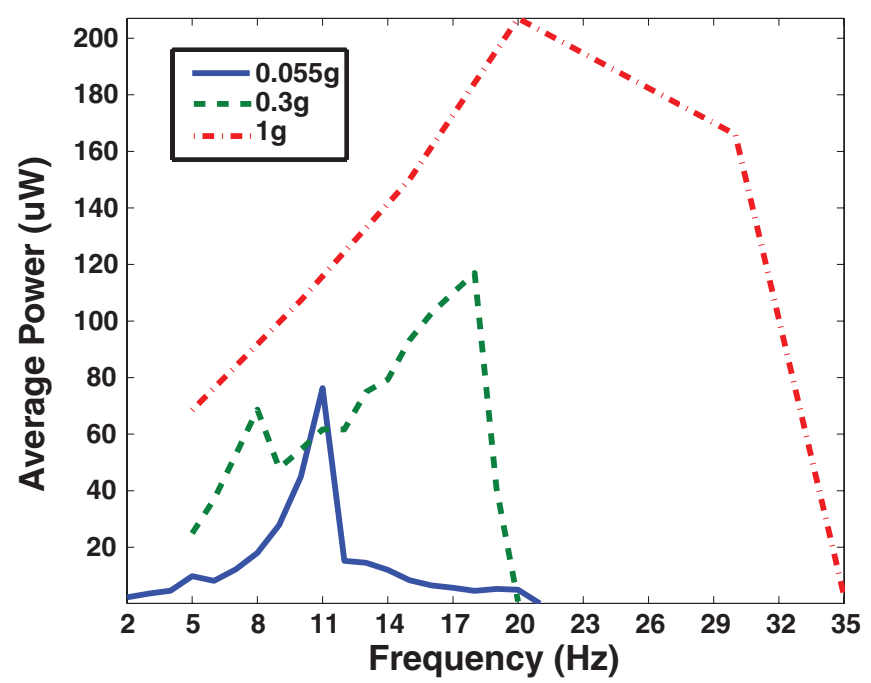

Figure 9. Frequency response of the PFIG to sinusoidal acceleration of varying magnitude. Average power is computed over several seconds in order to account for the decaying PFIG voltage waveform. The plot shows the unprecedented acceleration and frequency range of the PFIG.
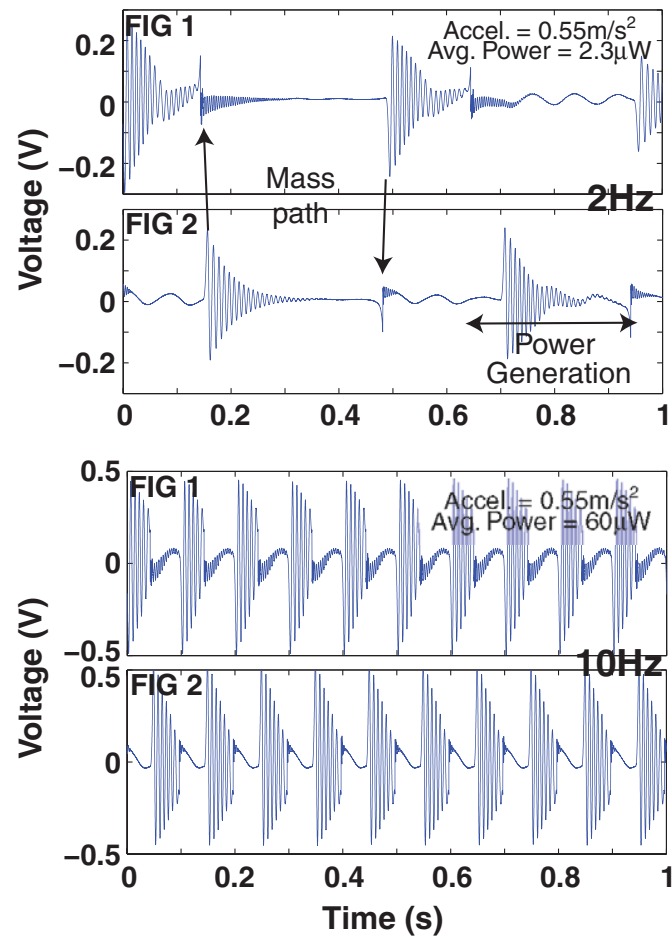

Figure 10. PFIG voltage during operation from a $0.54 \mathrm{~m} \mathrm{~s}^{-2}$ sinusoidal acceleration at 2 and $10 \mathrm{~Hz}$. The top and bottom voltage waveforms correspond to the two FIG devices as the inertial mass snaps back and forth between them. The release voltage at $10 \mathrm{~Hz}$ is larger than that at $2 \mathrm{~Hz}$ due to a larger actuation distance of the FIGs.

$10 \mathrm{~Hz}$. Additionally, since the inertial mass does not have much velocity, it stays in the vicinity of the FIG that has just been released and the magnetic latching mechanism influences the movement. That is the reason for the skewed voltage waveform of the bottom FIG. As the frequency increases to $10 \mathrm{~Hz}$, which is close to the natural frequency of the combined inertial mass/FIG system, the velocity and displacement are (a)
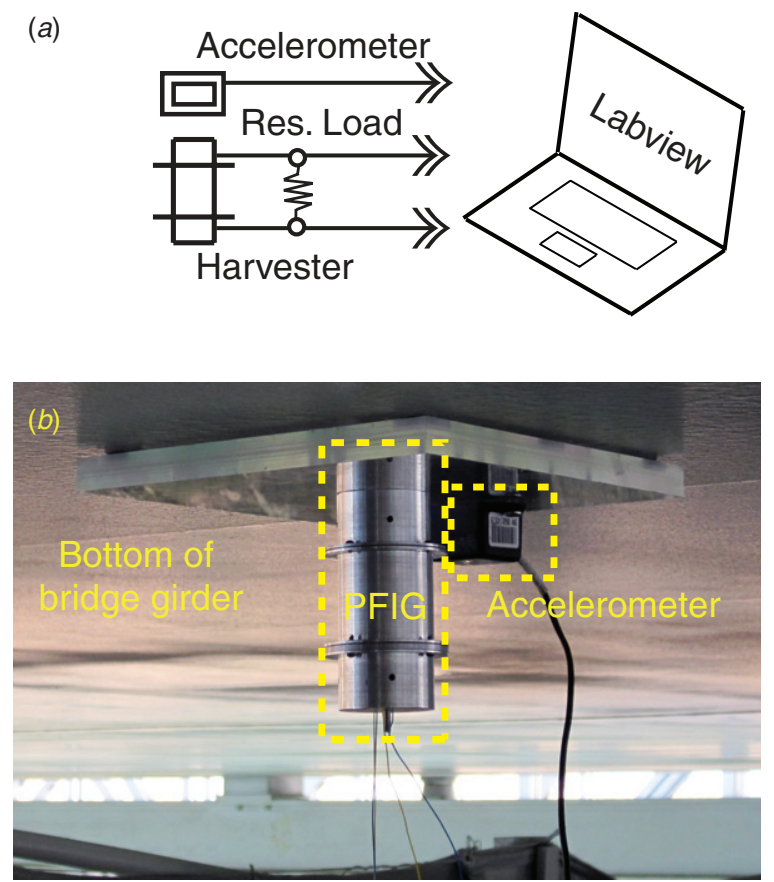

Figure 11. (a) Harvester test setup during field testing. Labview is used to simultaneously record the voltage produced by each FIG across a load as well as the acceleration on the bridge.

(b) Photograph of the harvester attached underneath the bridge girder alongside a Crossbow accelerometer.

increased, and the FIG motion is influenced less by the magnetic latch. Additionally, the higher velocity results in dynamic forces which play a role in the release distance. For example, at higher velocity the FIG has more momentum pushing it forward, and the release distance is not solely governed by the force of the FIG spring.

\subsection{New Carquinez bridge testing}

The PFIG harvester performance was tested on the NC bridge in Valejo, California. As discussed previously, the NC bridge is a suspension bridge carrying four lanes of west-bound traffic on interstate I-80. Testing was performed on the main span of the bridge. The harvester was fixed to an acrylic fixture alongside a Crossbow CXL02TG3 accelerometer. The fixture is magnetically attached to the bottom of the bridge girder. Each FIG is loaded with a matched $1.5 \mathrm{k} \Omega$ load and the voltage across the load is recoded simultaneously along with the output from the accelerometer using Labview. Figure 11(a) shows a diagram of the test setup, and figure $11(b)$ is a photograph of the PFIG alongside the accelerometer mounted on the bottom of the NC bridge.

The performance of the harvester was recorded at five evenly spaced locations between the south tower of the bridge and the center cable, with one of the measurements being taken past the center. Since, the bridge is symmetric, it was decided to test the harvester on approximately only half of the structure, while increasing the density of the measurement points. Figure 12 displays the results of this study. The circled numbers identify the recoding location on the bridge. The 2 min recordings are fairly consistent in that the harvester 


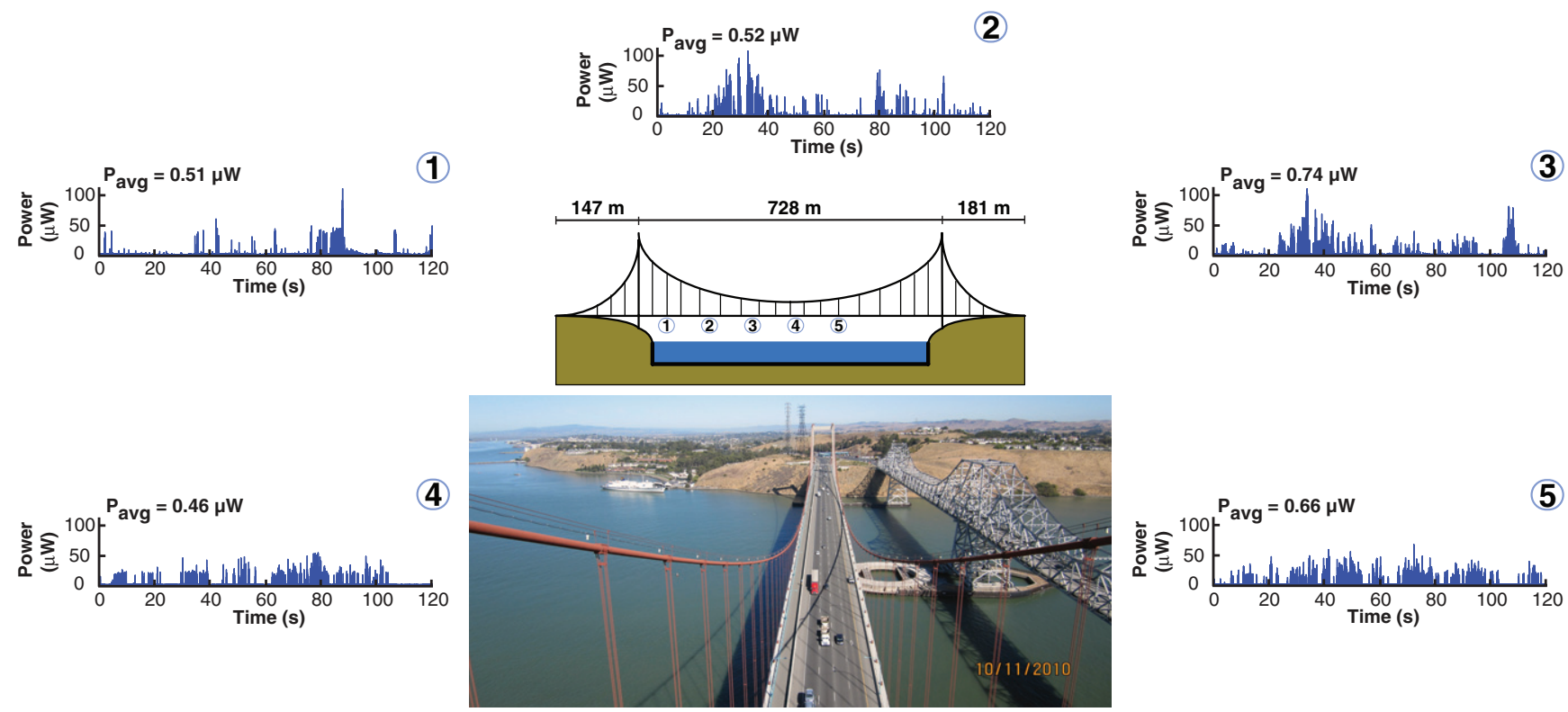

Figure 12. Average power generated by the PFIG while mounted underneath the NC bridge girder. The diagram of the bridge shows the approximate location of the harvester along the length of the bridge. A photograph of the main span of the NC bridge under routine traffic loading is shown. The PFIG harvester is able to generate a nearly identical average power response regardless of its placement without tuning or modification.

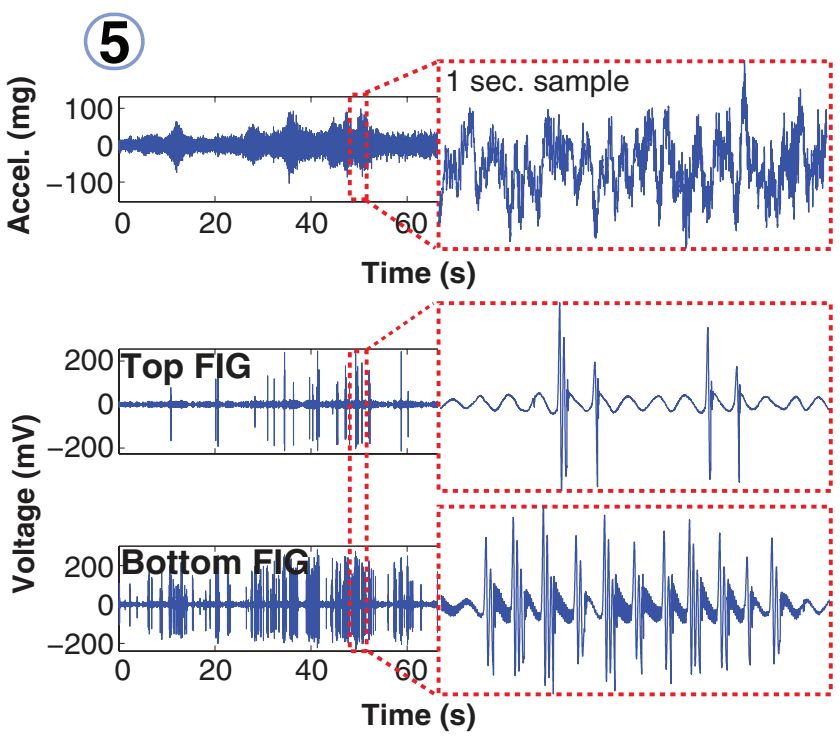

Figure 13. NC bridge acceleration for location 5 (top) and resulting FIG voltage outputs (bottom). The figure inserts show a 1 s close-up.

produced $0.46-0.74 \mu \mathrm{W}$ on average over this time. The PFIG was not modified, adjusted or tuned while being moved from location to location. The testing took place over the course of 1 day, and so the traffic on the bridge varied somewhat. Nonetheless, the PFIG was able to produce a nearly constant power supply without tuning. This is one of the core strengths of this technology, because the non-resonant operation allows for high versatility that will result in reduced installation complexity/cost, less maintenance and even enable certain applications which cannot be pursued with existing energy harvesting technologies.

Figure 13 shows the detailed recording made at location 5. The FIG voltage can be seen in relation to the bridge acceleration. The acceleration on the bottom of the girder is slightly higher than when the measurements were made on the deck (figure 1). This is fortuitous because the bottom of the girder is a prime sensor location for structural health monitoring. It is clear from figure 13 that the top FIG undergoes fewer actuation cycles than the bottom. While this is in part due to not fully eliminating the effect of gravity, there are two other important issues to consider. First, the PFIG operation is varying dynamically. Its response to the bridge acceleration is dependent on the initial conditions immediately prior to actuation. Second, as shown in figure 9, the PFIG $3 \mathrm{~dB}$ bandwidth, considering the lowest operating frequency as the 'center frequency', is $18 \mathrm{~Hz}$. As discussed in section 2, the real target is to make the bandwidth at least $30 \mathrm{~Hz}$, in order to capture a majority of the spectral power, not only for the NC bridge, but other bridge types as well. The lower bandwidth plays a role in the reduced actuation cycles for both the top and bottom FIGs.

\section{Harvester system design and interface electronics}

The electrical energy produced by the PFIG is not in a form usable by most electronic devices. The alternating (ac) voltage has to, at a minimum, be converted to a constant (dc) voltage. Additionally, the current PFIG harvester produces a relatively low voltage and so a boosting circuit is required to increase the dc voltage to a level typically used by electronics (i.e. 1-5 V). A system is being designed to manage the energy from the vibration harvester and supply it to a wireless sensor node (figure 14). Since the availability of bridge vibrations varies, and because the conversion efficiency is not high enough to directly power existing sensor technologies, the approach is to use the harvester to replenish the energy in a storage element that will periodically power the sensor node. 


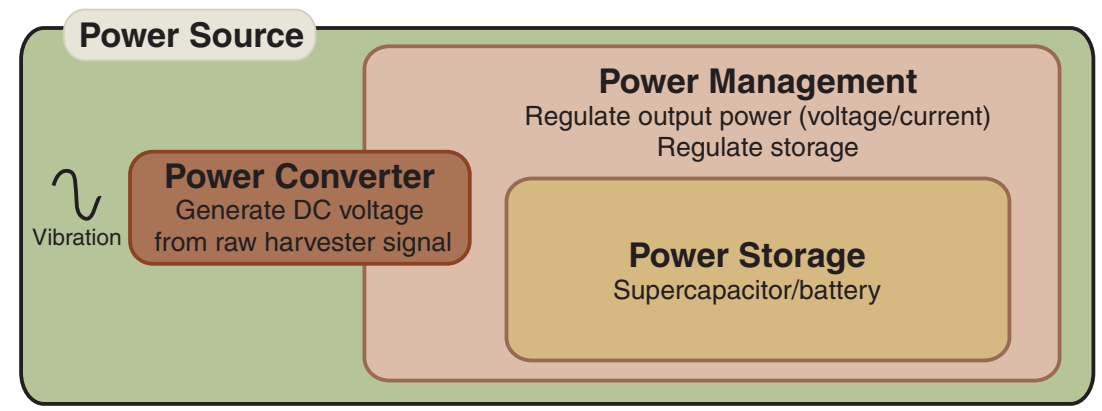

Figure 14. Hybrid wireless sensor power module. Renewable energy from traffic-induced bridge vibrations is used to replenish the charge on a storage element and regulated power is sent to the wireless sensor.

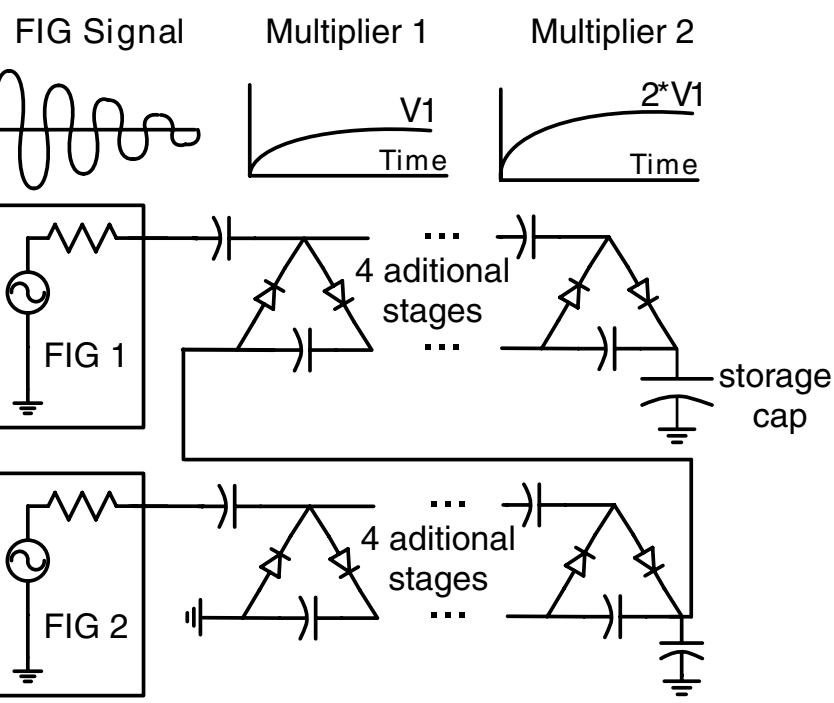

Figure 15. Power converter based on Cockcroft-Walton (CW) multiplier. Each FIG is connected to a six stage CW multiplier. The outputs of these multipliers are cascaded and stored on a capacitor.

This architecture relies on the duty cycle of the system being low enough so that the harvester has enough time to replenish the energy.

\subsection{Power converter design and implementation}

A preliminary version of the power converter block in figure 14 has been designed and tested. Rectifying, boosting and storing the output from the FIGs presents a number of unique challenges not encountered with resonant harvesters. First, the FIG output waveform has a low frequency $(152 \mathrm{~Hz})$ as far as electronics are concerned. Secondly, the traffic-induced vibrations are not steady nor are they frequent. Lastly, the FIGs produce a low and decaying output voltage. Rather than using a rectifier followed by a boost circuit, as is typical in vibration harvester interface circuits, a charge pump-based approach is favored in this implementation. This approach allows rectification and $\mathrm{dc}-\mathrm{dc}$ conversion to be performed at the same time. Additionally, dc-dc converters typically require the generation of a clocking signal(s), which would require additional power. In a charge pump, the ac voltage waveform itself can be used for switching. The design of the power conversion block is shown in figure 15. Each FIG

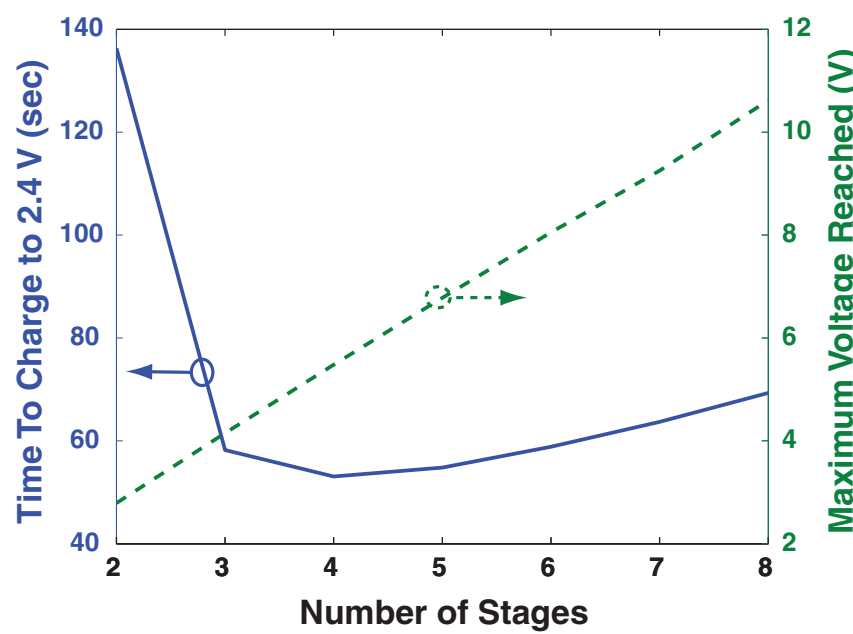

Figure 16. Simulation showing the time to charge the storage capacitor to $2.4 \mathrm{~V}$ (left axis) and the maximum voltage that can be reached if sufficient time were allowed (right axis) as a function of multiplier stages. These simulations take into account the cascading of two $n$-stage CW multipliers as is done with the FIG outputs.

is attached to a Cockcroft-Walton (CW) multiplier [21]. The outputs of the two multipliers are cascaded to further increase the voltage and to combine the two outputs into one. The resulting charge is stored on a capacitor.

The final voltage of a CW multiplier is given by

$$
V_{\text {out }}=2 \cdot n \cdot V_{\text {peak }} \text {, }
$$

where $n$ is the number of stages and $V_{\text {peak }}$ is the FIG peak voltage. This is an idealized approximation and assumes no parasitic losses and diode drops. The choice of $n$ is a tradeoff between charge time and $V_{\text {out }}$. Figure 16 shows an LTSpice simulation of the CW multiplier scheme as a function of $n$. The simulation takes into account the cascading scheme used for the two FIG outputs, so that the results are for two $n$-stage CW multipliers connected in series. It shows the interplay between charge time (left axis) and output voltage (right axis). The goal is to generate a $2.4 \mathrm{~V}_{\mathrm{DC}}$ supply. The FIGs are modeled as an ac voltage source followed by a $1.5 \mathrm{k} \Omega$ resistor in series. In order to model the voltage decay, a voltage waveform from a previous generation of the PFIG architecture was used [14]. It has a peak value of $375 \mathrm{mV}$. Ideal capacitors and nonideal Schottky diodes (BAT54WS) are used in the simulation. As shown, $n=4$ stages achieves the minimum charge time. 


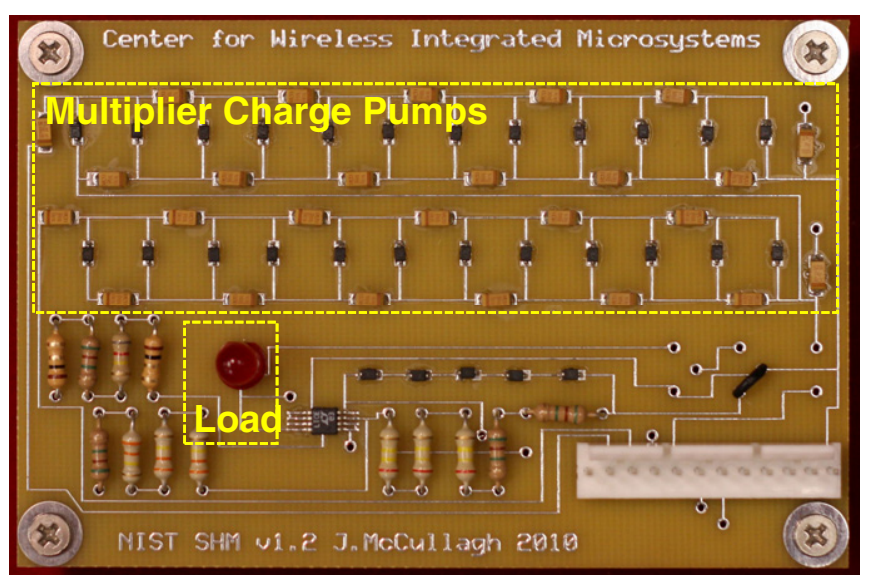

Figure 17. Printed circuit board implementation of power converter.

With three stages or less, the voltage multiplier cannot reach $2.4 \mathrm{~V}$ due to parasitic losses. When five or more stages are used, it takes more time to charge the extra capacitance of the multiplier. However, the PFIG harvester has to be able to operate from non-periodic signals, and signals with lower peak voltages. As shown in (18), the more stages there are, the higher the output voltage. This relationship is shown in figure 16 using the right axis. In these simulations sufficient time is allowed for the multiplier to reach a steady value. In order to reduce the charge time while keeping the final output voltage around $2.4 \mathrm{~V}$, six stages were selected for the present implementation.

The power converter block is implemented on a printed circuit board using off-the-shelf components (figure 17). Schottky diodes (BAT54WS) with a turn on voltage of $180 \mathrm{mV}$ and $10 \mu \mathrm{F}$ capacitors are used to construct the multiplier stages. The outputs of the two multipliers are cascaded and the resulting charge is stored on a $100 \mu \mathrm{F}$ electrolytic capacitor. Several different load devices were used to mimic power delivery to a sensor node, including a ring oscillator that actuated a piezoelectric buzzer and an LED. The oscillator is made out of three NC7SP04 inverters.

\subsection{Harvester system testing}

In order to show the viability of using harvested energy from bridges, the PFIG system was subjected to bridge-like vibrations on the shaker table by reproducing a 20 s recording from the field tests. The acceleration produced by the shaker table can be seen in the top of figure 18. The peak-to-peak acceleration is slightly larger than what has been recorded on bridges. The voltage on the storage capacitor at the end of the multiplier is shown in the bottom plot of figure 18. Some ripples can be seen on the rising voltage. The ripples result from parasitic discharging of the multiplier circuit in between acceleration spikes.

This test demonstrates the operation of a vibration harvester from random (non-periodic) traffic-induced bridge vibrations. Additionally, the power conversion system shows for the first time that the decaying voltage produced by PFIG

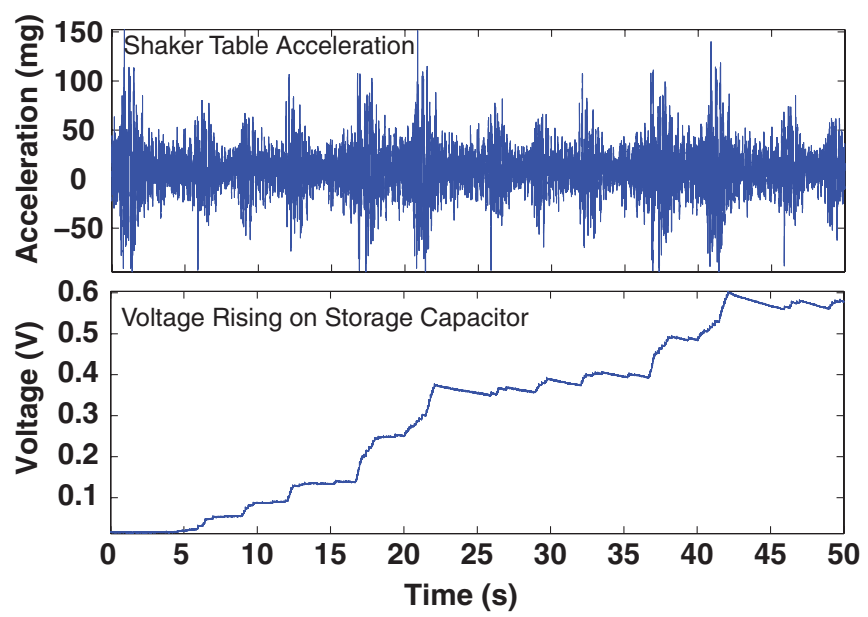

Figure 18. PFIG used for harvesting the non-periodic wide-band vibrations shown in the top plot. The voltage of the storage capacitor is seen rising over time in the bottom graph.

operation could be rectified, boosted and stored. However, further work on the power conversion system is needed in order to allow it to work under slowly occurring traffic-induced bridge vibrations. The main challenges that exist are to overcome the power lost due to the diode turn on voltages and the energy dissipated from the multiplier capacitors in between actuation cycles. Simulations reveal that the total system efficiency (total energy in versus total energy stored on the final capacitor) from periodic vibrations at $2 \mathrm{~Hz}$ is $13 \%$. On the flip side, the harvester design and efficiency improvements will help to alleviate power conversion challenges. The harvester could stand to benefit from a reduction in the output impedance and an increase in the peak output voltages produced by the FIGs. Additionally, by reducing the minimum acceleration to which the harvester is able to respond, it is expected that the frequency of actuation cycles will increase because the average bridge accelerations are closer to 20-30 mg rather than $55 \mathrm{mg}$.

\section{Performance and discussion}

The performance of the PFIG harvester and power conversion electronics is summarized in table 2. This effort is part of a larger project [5] to develop wireless sensing technology for bridge health monitoring. A very low power wireless sensing platform is being developed to complement the use of renewable energy. At the same time, converted energy from bridge vibrations will be coupled with a number of other renewable energy sources to power the sensor nodes. While the current power levels achieved on the bridge are not high enough, an improvement of at least $10 \times$ is desirable, there is a clear path forward. In the present implementation, the electromagnetic transducer does not involve any complicated magnetic circuits and geometry, and the incorporation of such enhancements will likely allow a significant increase in the output voltage. The coil to magnet volume ratio is quite high, considering their dimensions, which means that with proper optimizations the same output voltage can be generated with 


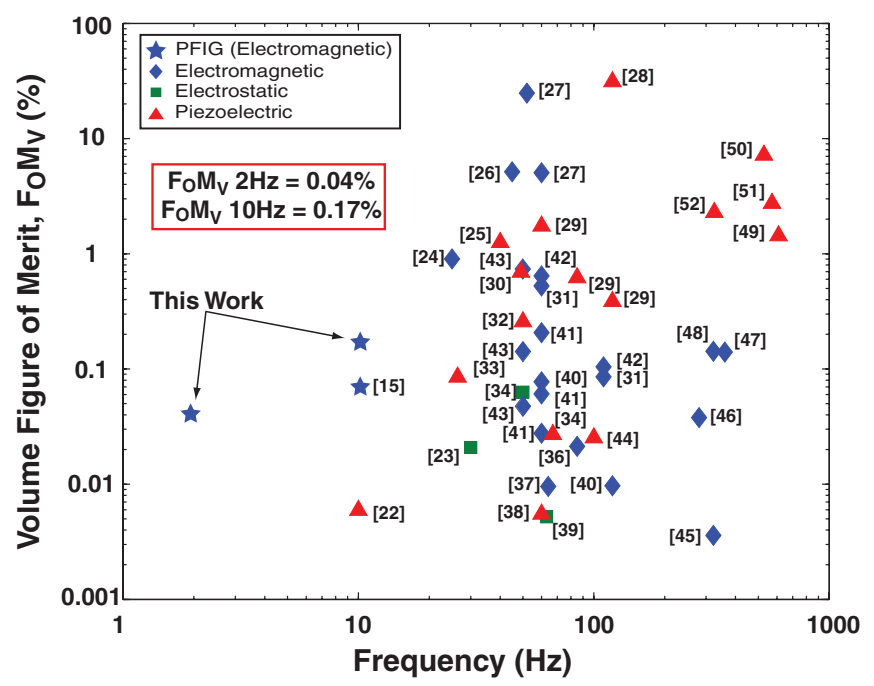

Figure 19. Volume FoMv comparison of the PFIG to the state-of-the-art in vibration scavengers.

Table 2. PFIG performance summary.

\begin{tabular}{ll}
\hline Minimum acceleration & $0.54 \mathrm{~m} \mathrm{~s}^{-2}$ \\
Internal volume & $43 \mathrm{~cm}^{3}$ \\
Total volume & $68 \mathrm{~cm}^{3}$ \\
Avg. power $\left(0.54 \mathrm{~m} \mathrm{~s}^{-2}, 2 \mathrm{~Hz}\right)$ & $2.3 \mu \mathrm{W}$ \\
Peak power $\left(0.54 \mathrm{~m} \mathrm{~s}^{-2}, 2 \mathrm{~Hz}\right)$ & $57 \mu \mathrm{W}$ \\
Avg. power on NC bridge & $0.47-0.75 \mu \mathrm{W}$ \\
Bandwidth $\left(0.54 \mathrm{~m} \mathrm{~s}^{-2}\right)$ & $18 \mathrm{~Hz}$ \\
Volume figure of merit, FoMv $\left(0.54 \mathrm{~m} \mathrm{~s}^{-2}\right)$ & $0.04 \%$ \\
\hline
\end{tabular}

a lower internal impedance. Lastly, by reducing the minimum acceleration needed for the harvester to operate, the PFIG will be able to respond to more of the acceleration peaks, which would increase the average power.

In order to compare the harvester's efficiency to the stateof-the-art, the non-regulated output power is used because most other works do not have management electronics. Figure 19 shows the volume figure of merit (FoMv) [18] of the PFIG as compared to the state of the art [17, 22-52], and to a previous electromagnetic PFIG designed for higher amplitude [17] vibrations. The FoMv when calculated at the extreme low operating frequency of $2 \mathrm{~Hz}$ is $0.04 \%$, and it rises to $0.17 \%$ for $10 \mathrm{~Hz}$ operation. This work significantly outperforms other efforts in the low end of the frequency spectrum $(\leqslant 10 \mathrm{~Hz})$.

The bandwidth performance of the PFIG is quite good. Considering bandwidth as the $50 \%$ power reduction from the minimum frequency of interest, in this case $2 \mathrm{~Hz}$, the PFIG has a bandwidth of $18 \mathrm{~Hz}$ when operating from $0.54 \mathrm{~m} \mathrm{~s}^{-2}$ acceleration. At higher acceleration, its bandwidth improves significantly and was tested to be as high as $30 \mathrm{~Hz}$. However, more important than the bandwidth itself is the demonstration of the efficient and robust operation of a vibration harvesting system in ambient conditions with nonperiodic arbitrary vibrations.

\section{Conclusion}

This paper presented the design, fabrication and testing of an electromagnetic inertial micro power generation system for scavenging the very low-amplitude, low frequency and nonperiodic vibrations present on bridges. The fabricated device generated a peak power of $57 \mu \mathrm{W}$ and an average power of $2.3 \mu \mathrm{W}$ from an input acceleration of $0.54 \mathrm{~m} \mathrm{~s}^{-2}(55 \mathrm{mg})$ at only $2 \mathrm{~Hz}$. The device bandwidth at $55 \mathrm{mg}$ is $18 \mathrm{~Hz}$. It has a volume FoMv of $0.04 \%$ when computed at $2 \mathrm{~Hz}$, which is state of the art by a factor of 10 in the $<10 \mathrm{~Hz}$ frequency range. The internal volume of the generator is $43 \mathrm{~cm}^{3}$ (68 $\mathrm{cm}^{3}$ including casing). The generator is capable of operating over an unprecedentedly large acceleration range $\left(0.54-9.8 \mathrm{~m} \mathrm{~s}^{-2}\right.$ ) and frequency range (up to $30 \mathrm{~Hz}$ ) without any modifications or tuning. Its operation was verified along the bottom of the NC bridge girder, where the harvester produced $0.5-0.75 \mu \mathrm{W}$ of average power without any modifications, tuning or manipulation during installation.

\section{Acknowledgments}

The authors would like to thank the National Institute of Standards and Technology (NIST) for funding this effort as part of the Technology Innovation Program (TIP) under Cooperative agreement number 70NANB9H9008. Additional support was provided by the Michigan Department of Transportation (MDOT), and the California Department of Transportation (Caltrans). We would like to thank our collaborators Drs Jerome Lynch and Masahiro Kurata for providing the bridge acceleration data and Ed Thometz from Caltrans for his invaluable assistance during field testing.

\section{References}

[1] Sohn H, Farrar C R, Hemez F M, Shunk D D, Stinemates S W, Nadler B R and Czarnecki J J 2004 Review of Structural Health Monitoring Literature from 1996-2001 (Los Alamos: Los Alamos National Laboratory)

[2] Lynch J P 2007 An overview of wireless structural health monitoring for civil structures Phil. Trans. R. Soc. A $365345-72$

[3] Lynch J P, Law K H, Kiremidjian A S, Carryer E, Farrar C R, Sohn H, Allen D W, Nadler B and Wait J R 2004 Design and performance validation of a wireless sensing unit for structural monitoring applications Struct. Eng. Mech. 17 393-408

[4] US Department of Transportation 2010 Our Nation's Highways: 2010 http://www.fhwa.dot.gov/ policyinformation/pubs/p110023/fig7_3.cfm

[5] Kurata M et al 2010 A two-tiered self-powered wireless monitoring system architecture for bridge health management Proc. SPIE 7649 76490k

[6] Nagayama T, Jung H-J, Spencer B F, Jang S, Mechitov K, Cho S, Ushita M, Yun C-B, Agha G and Fujino Y 2010 International collaboration to develop a structural health monitoring system utilizing wireless smart sensor network and its deployment on a cable-stayed bridge 5th World Conf. on Structural Control and Monitoring (Tokyo, Japan)

[7] Park J-W, Jung H-J, Jo H, Jang S and Spencer B F Jr 2010 Feasibility study of wind generator for smart wireless sensor node in cable-stayed bridge Proc. SPIE 7647764747 
[8] Farinholt K M, Miller N, Sifuentes W, MacDonald J, Gyuhae P and Farrar C R 2010 Energy harvesting and wireless energy transmission for embedded SHM sensor nodes Struct. Health Monit. 9 269-80

[9] Mascarenas D L, Flynn E B, Todd M D, Overly T G, Farinholt K M, Gyuhae P and Farrar C R 2010 Experimental studies of using wireless energy transmission for powering embedded sensor nodes J. Sound Vib. 329 2421-33

[10] Galchev T, McCullagh J, Peterson R L, Najafi K and Mortazawi A 2011 Energy harvesting of radio frequency and vibration energy to enable wireless sensor monitoring of civil infrastructure Nondestructive Characterization for Composite Materials, Aerospace Engineering, Civil Infrastructure and Homeland Security (7-10 March 2011) p 798314

[11] Sazonov E, Haodong L, Curry D and Pillay P 2009 Self-powered sensors for monitoring of highway bridges IEEE Sens. J. 9 1422-9

[12] Ashebo D B, Chin An T, Jun W and Gang L 2008 Feasibility of energy harvesting for powering wireless sensors in transportation infrastructure applications Proc. SPIE $6934069340 Y$

[13] Williams C B, Pavic A, Crouch R S, Woods R C and Society Experimental Mechanics, Inc. 1998 Feasibility study of vibration-electric generator for bridge vibration sensors Proc. 16th Int. Modal Analysis Conf., IMAC Vols 1 and 2 (SEMI, Bethel) vol 3243 pp 1111-7

[14] Galchev T, Kim H and Najafi K 2009 Non-resonant bi-stable frequency increased power generator for low-frequency ambient vibration 15th Int. Conf. on Solid-State Sensors, Actuators, and Microsystems Transducers '09 (Denver, CO) pp 632-5

[15] Galchev T, Kim H and Najafi K 2011 Micro power generator for harvesting low-frequency and non-periodic vibrations IEEE/ASME J. Microelectromech. Syst. at press

[16] Galchev T, McCullagh J, Peterson R L and Najafi K 2010 A vibration harvesting system for bridge health monitoring applications PowerMEMS (Leuven, Belgium) pp 179-82

[17] Galchev T 2010 Energy scavenging from low frequency vibrations PhD Thesis University of Michigan, Ann Arbor

[18] Mitcheson P D, Yeatman E M, Rao G K, Holmes A S and Green T C 2008 Energy harvesting from human and machine motion for wireless electronic devices Proc. IEEE 96 1457-86

[19] Kulah H and Najafi K 2008 Energy scavenging from low-frequency vibrations by using frequency up-conversion for wireless sensor applications IEEE Sens. J. 8 261-8

[20] Kulah H and Najafi K 2004 An electromagnetic micro power generator for low-frequency environmental vibrations MEMS '04 pp 237-40

[21] Pan F and Samaddar T 2006 Charge Pump Circuit Design (New York: McGraw-Hill)

[22] Renaud M, Fiorini P, van Schaijk R and van Hoof C 2009 An impact based piezoelectric harvester adapted to low frequency environmental vibrations Int. Solid-State Sensors, Actuators and Microsystems Conf. Transducers '09 pp 2094-7

[23] Miao P, Mitcheson P D, Holmes A S, Yeatman E M, Green T C and Stark B H 2006 MEMS inertial power generators for biomedical applications Microsyst. Technol. 121079

[24] Chang S C, Yaul F M, Dominguez-Garcia A, O'Sullivan F, Otten D M and Lang J 2009 Harvesting energy from moth vibrations during flight PowerMEMS (Washington, DC) pp 57-60

[25] Hammond K et al 2005 An integrated node for energy-scavenging, sensing, and data-transmission: applications in medical diagnostics $2 n d$ Int. Workshop on
Wearable and Implantable Body Sensor Networks (London, $U K)$ p 58

[26] Ayala I, Zhu D, Tudor M and Beeby S 2009 Autonomous tunable energy harvester PowerMEMS (Washington, DC) pp 49-52

[27] Beeby S P, Torah R N, Tudor M J, Glynne-Jones P, O'Donnell T, Saha C R and Roy S 2007 A micro electromagnetic generator for vibration energy harvesting J. Micromech. Microeng. 171257

[28] Khbeis M, McGee J and Ghodssi R 2009 Development of a simplified hybrid ambient low frequency, low intensity vibration energy scavenger system Int. Solid-State Sensors, Actuators and Microsystems Conf. Transducers '09 pp 525-8

[29] Roundy S 2003 Energy scavenging for wireless sensor nodes with a focus on vibration to electricity conversion $P h D$ Thesis University of California, Berkeley

[30] Berdy D, Srisungsitthisunti P, Xu X, Rhoads J, Jung B and Peroulis D 2009 Compact low frequency meandered piezoelectric energy harvester PowerMEMS (Washington, DC) pp 71-4

[31] Ching N N H, Wong H Y, Li W J, Leong P H W and Wen Z 2001 A laser-micromachined vibration to electrical power transducer for wireless sensing systems 11th Int. Conf. Solid-State Sensors and Actuators (Munich, Germany)

[32] Tanaka H, Ono G, Nagano T and Ohkubo N 2005 Electric power generation using piezoelectric resonator for power-free sensor node Custom Integrated Circuits Conf., 2005: Proc. IEEE 2005 pp 97-100

[33] Challa V R, Prasad M G, Yong S and Fisher F T 2008 A vibration energy harvesting device with bidirectional resonance frequency tunability Smart Mater. Struct. 17015035

[34] Despesse G, Chaillout J J, Dekkaki I, Jager T, Leger J M, Vassilev A, Basrour S and Charlot B 2005 High damping electrostatic system for vibration energy scavenging $N S T I$ Nanotechnology Conf. and Trade Show (Anaheim, CA) pp 371-4

[35] Zhu D, Beeby S, Tudor M and Harris N R 2009 A self powered tag for wireless structure health monitoring in aeronautical applications PowerMEMS (Washington, DC) pp 201-4

[36] Lee J M H, Yuen S C L, Li W J and Leong P H W 2003 Development of an AA size energy transducer with micro resonators Int. Symp. on Circuits and Systems, ISCAS (Bangkok, Thailand) pp 876-9

[37] Li W J, Wen Z, Wong P K, Chan G M H and Leong P H W 2000 A micromachined vibration-induced power generator for low power sensors and robotic systems World Automation Congress 8th Int. Symp. on Robotic Applications (Maui, HI)

[38] White N M, Glynne-Jones P and Beeby S P 2001 A novel thick-film piezoelectric micro-generator Smart Mater. Struct. 10 850-2

[39] Miki D, Honzumi M, Suzuki Y and Kasagi N 2009 MEMS electret generator with electrostatic levitation PowerMEMS (Washington, DC) pp 169-72

[40] Li W J, Ho T C H, Chan G M H, Leong P H W and Hiu Yung W 2000 Infrared signal transmission by a laser-micromachined, vibration-induced power generator 43rd IEEE Midwest Symp. on Circuits and Systems pp 236-9

[41] F Solutions Ferro Solutions VE460 http://www.ferrosi.com/files/VEH460_May09.pdf

[42] Ching N N H, Wong H Y, Li W J, Leong P H W and Wen Z 2002 A laser-micromachined multi-modal resonating power transducer for wireless sensing systems Sensors Actuators A 97-98 685-90

[43] Perpetuum Perpetuum PMG FSH Datasheet http://www. perpetuum.com/resources/PMG FSH Datasheet.pdf 
[44] Ng T H and Liao W H 2005 Sensitivity analysis and energy harvesting for a self-powered piezoelectric sensor J. Intell. Mater. Syst. Struct. 16 785-97

[45] Glynne-Jones P, Tudor M J, Beeby S P and White N M 2004 An electromagnetic, vibration-powered generator for intelligent sensor systems Sensors Actuators A $110344-9$

[46] Wang P, Dai X, Zhao X and Ding G 2009 A micro electromagnetic vibration energy harvester with sandwitched structure and air channel for high energy conversion PowerMEMS (Washington, DC) pp 296-9

[47] Beeby S, Tudor J, Torah R, Koukharenko E, Roberts S, O'Donnell T and Roy S 2006 Macro and micro scale electromagnetic kinetic energy harvesting generators $D T I P$ MEMS MOEMS (Stresa, Italy)

[48] El-hami M, Glynne-Jones P, White N M, Hill M, Beeby S, James E, Brown A D and Ross J N 2001 Design and fabrication of a new vibration-based electromechanical power generator Sensors Actuators A 92 335-42
[49] Elfrink R et al 2009 Vibration energy harvesting with aluminum nitride-based piezoelectric devices J. Micromech. Microeng. 19094005

[50] Park J C, Lee D H, Park J Y, Chang Y S and Lee Y P 2009 High performance piezoelectric MEMS energy harvester based on D33 mode of PZT thin film on buffer-layer with PBTIO3 inter-layer Int. Solid-State Sensors, Actuators and Microsystems Conf. Transducers '09 pp 517-20

[51] Hua-Bin F, Jing-Quan L, Zheng-yi X, Lu D, Li W, Di C, Bing-chu C and Yue L 2006 Fabrication and performance of MEMS-based piezoelectric power generator for vibration energy harvesting Microelectron. J. 37 1280-4

[52] Elfrink R, Renaud M, Kamel T M, de Nooijer C, Jambunathan M, Goedbloed M, Hohfeld D, Matova S and van Schaijik R 2009 Vacuum packaged MEMS piezoelectric vibration energy harvesters PowerMEMS (Washington, DC) pp 67-70 